\title{
Engrailed 2 (EN2) acts as a glioma suppressor by inhibiting tumor proliferation/invasion and enhancing sensitivity to temozolomide
}

\author{
Tengfei Li', Wanchun Yang 1,2, Mao Li', Shuxin Zhang ', Xingwang Zhou', Mingrong Zuo', Qiuyun Yuan²,
} Mina Chen ${ }^{1,2^{*}}$ and Yanhui Liu ${ }^{1 *}$ (D)

\begin{abstract}
Background: Glioma is one of the most malignant brain tumors and accounts for the majority of brain cancer related death. Despite progress on mechanistic studies, current understandings of the initiation and progression of glioma are still incomplete. Previous studies demonstrate that Engrailed-2 (EN2), a homeobox-containing transcription factor, is associated with tumorigenesis in a range of cancers heterogeneously, however, the profiles of EN2 expression and its potential functions in gliomas remain unclear.

Methods: Real-time PCR was used to identify the expression of EN2 in glioma tissues. To study the biological function of EN2 in glioma, we compared the cell viability and proliferation profiles between EN2 overexpressed and control cells using cell counting kit-8 (CCK8) assay, EdU incorporation assay and colony formation assay. Flow cytometry and Hoechst staining assays were performed to investigate the role of EN2 on glioma cell death. Finally, wound healing and transwell assays were carried out to investigate the role of EN2 on glioma cell invasion.

Results: We identified that EN2 was downregulated in human gliomas compared with paired adjacent normal tissues and negatively associated with glioma malignancy. Elevated EN2 expression inhibits cell proliferation, enhances glioma sensitivity to temozolomide and inhibits migration/invasion of glioma cells.
\end{abstract}

Conclusions: Our data identify a novel function of EN2 in glioma suppression and provide potential therapeutic targets for glioma therapy.

Keywords: EN2, Glioma, Temozolomide, Cell invasion

\section{Background}

Glioma is one of the most prevalent malignant and lethal tumors in the central nervous system, which displays aggressive growth and diffuse invasion [1,2]. Gliomas including astrocytomas, oligodendrogliomas and

\footnotetext{
*Correspondence: chenmina2010@scu.edu.cn; liuyh@scu.edu.cn

1 Department of Neurosurgery, State Key Laboratory of Biotherapy, West

China Hospital, Sichuan University, 37 Guoxue Alley, Chengdu 610041,

Sichuan, People's Republic of China

${ }^{2}$ Neuroscience \& Metabolism Research, State Key Laboratory

of Biotherapy, West China Hospital, Sichuan University, 37 Guoxue Alley,

Chengdu 610041, Sichuan, People's Republic of China
}

glioblastoma multiforms (GBM), are classified as grade I to IV based on histological features and genetic alterations [3]. Despite standard treatment comprised of maximal safe surgical resection, radiotherapy plus concomitant and maintenance temozolomide chemotherapy $[4,5]$, the prognosis for glioma patients remains poor and almost all patients relapse inevitably. Particularly, the median survival time of patients with GBM remains approximately 1 year, and the 5 -year overall survival rate is less than $5 \%[6,7]$.

Glioma evolves rapidly by acquiring new mutations or altered gene expressions for drug resistance [8]. Studies 
have interrogated a network of gene expression profiles to identify novel genes and critical pathways for glioma malignancy [9]. Transcription factor (TF) regulates gene expression by translating cis-regulatory codes into specific gene-regulatory events [10], and acts as a functional unit in cell fate decisions in many cell types and systems including cancer. Therefore, electing TF as a rational target for cancer therapy is a promising concept [11]. Even though progressive technologies and systematic analysis have cataloged a landscape of TF alternations and gene expression changes in glioma [12-15], current understandings of gliomagenesis are still incomplete.

Engrailed-2 (EN2) gene encodes a homeobox-containing transcription factor and participates in the regionalization, patterning and cell differentiation in early brain development [15-17]. Accumulated evidence demonstrates that EN2 is highly associated with tumorigenesis in some types of cancers [18-26], however, controversial results show that EN2 is silenced in other cancers [27, 28]. As for glioma, it remains unclear about EN2 expression pattern and potential functions. Here, using clinical samples combined with functional approaches, we demonstrate that EN2 is a novel suppressor of glioma tumorigenesis. EN2 expression is downregulated in human gliomas compared to adjacent brain tissues, which is negatively associated with glioma malignancy. Elevated EN2 expression inhibits cell proliferation and enhances glioma sensitivity to temozolomide. Moreover, EN2 blocks the invasion of glioma cells by inhibiting MMP9 expression. Our data identify a novel function of EN2 in glioma suppression and provides potential targets for glioma therapy.

\section{Materials and methods}

\section{Patients and samples}

All the human studies were approved by the Institutional Review Board of West China Hospital of Sichuan University and all patients provided written informed consent. A total of 75 patients, operated between Jun 2016 and Jan 2019 at the West China Hospital of Sichuan University with primary gliomas diagnosed, were included in this study to examine the mRNA levels of EN2 (Fig. 1a). The pathological diagnosis of glioma was confirmed and classified according to the World Health Organization (WHO) criteria by two clinical pathologists in a blinded manner.

\section{Cell culture}

Human glioma cell line U251 was used to investigate EN2 function in this study. U251 cell line was purchased from the Shanghai Institute of Biochemistry and Cell Biology, Chinese academy of sciences (China). Cells were cultured in Dulbecco's Modified Eagle's Medium (DMEM,
HyClone, Thermo Fisher Scientific, USA) supplemented with $10 \%$ fetal bovine serum (FBS, PAN Biotech, Germany) and $1 \%$ penicillin-streptomycin antibiotic mixture (Cellgro, USA). All cells were cultivated in an incubator with constant temperature containing $5 \% \mathrm{CO}_{2}$ atmosphere at $37^{\circ} \mathrm{C}$.

\section{Lentiviral construct and overexpression}

The EN2 lentiviral vector (Ubi-MCS-3FLAG-CBhgcGFP-IRES-puromycin) and control lentiviral were constructed by Shanghai Genechem Co., Ltd. (China). For lentivirus transduction, U251 cells were cultured for $24 \mathrm{~h}$ in a 12-well plate, and transfection efficiency was determined by an inverted fluorescence microscope. Afterward, puromycin $(2.0 \mu \mathrm{g} / \mathrm{mL})$ was used to screen infected cells to acquire stable EN2-overexpressed cells (Flag-EN2) and control cells (Ctrl). Cells were harvested and validated for subsequent experiments.

\section{Transcriptome sequencing}

Total RNA was isolated cell samples with Trizol reagent according to the manufacturer's protocol, and sequenced by Novogene (China). Reads were mapped to GRCh37. p13 genome and annotation with STAR using ENCODE recommended arguments. Gene-level read counts generated by STAR were used for differential expression analysis with the DESeq2 package. Log2 fold change and adjusted $p$ values of genes generated by DESeq2 were used for visualization using $R$.

\section{Cell viability and proliferation assay}

Cell viability was determined using Cell Counting Kit-8 (Dojindo China, China). Briefly, U251 cells were seeded at a volume of $100 \mu \mathrm{L}$ and density of 1500 cells/well counting by the hemocytometer in 96-well plates and incubated in 3 days for CCK8 assay every $24 \mathrm{~h}$. CCK-8 solution $(10 \mu \mathrm{L})$ at a 1:10 dilution with FBS-free DMEM $(100 \mu \mathrm{L})$ was added to each well followed by a further $3 \mathrm{~h}$ incubation under $5 \% \mathrm{CO}_{2}$ at $37{ }^{\circ} \mathrm{C}$. Relative absorbance was automatically measured at $450 \mathrm{~nm}$ wavelength on a microplate reader. The cell viability was calculated by the mean optical density (OD, absorbance). All experiments were performed three times, and values were plotted by averaging duplicated wells.

The proliferation of U251 cells was detected by EdU incorporation assay according to the manufacturer's protocol from the Cell-Light EdU (5-ethynyl-2'deoxyuridine) Apollo-567 In Vitro Imaging Kit (RiboBio, China).

For the colony formation assay, U251 cells were suspended and plated in $10 \mathrm{~cm}$ plates at low density (200 cells/plate) and cultured in 10\% FBS complete medium for 2 weeks. The cells were washed twice with 


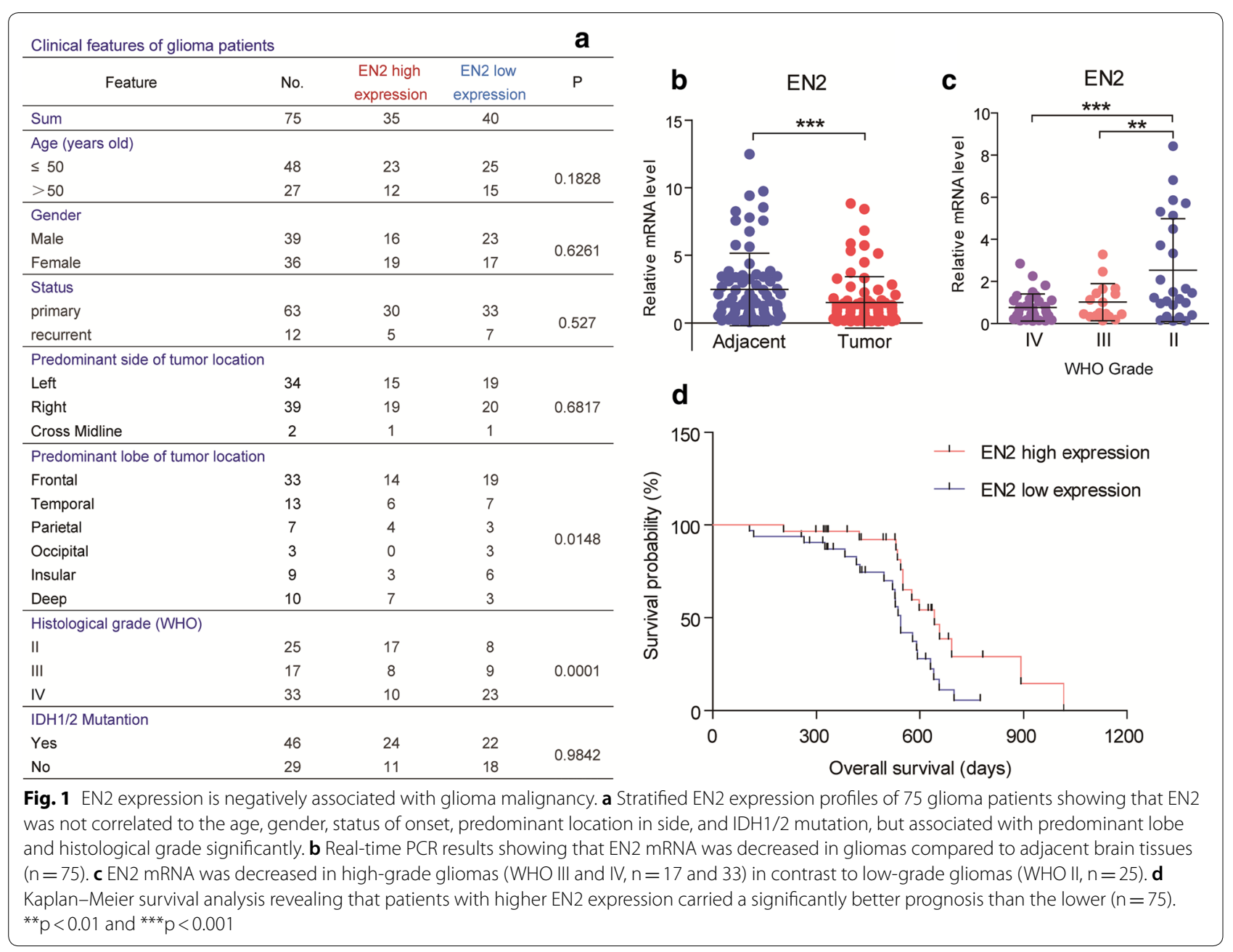

phosphate-buffered saline and stained with $0.5 \%$ crystal violet for $20 \mathrm{~min}$ and photographed. The colony with more than 50 cells were considered for enumeration using an inverted microscope.

\section{Cell death assay}

Early apoptosis of U251 cells was detected by Annexin V Alexa Fluor647/7-AAD kit (Beijing 4A Biotech, China) followed by flow cytometry on a Beckman cytoflex. Briefly, cells were plated in 6-wells plate overnight. When it was about $80-90 \%$ confluence, cells were digested, washed in pre-cooling PBS, then suspended in prepared binding buffer. $100 \mu \mathrm{L}$ of suspension was transferred to a new tube followed by the addition of $10 \mu \mathrm{L}$ of Annexin V Alexa Fluor647 and $5 \mu \mathrm{L}$ of 7 -AAD, then incubated in the dark at room temperature for $15 \mathrm{~min}$ and served it on ice followed by flow cytometry.

To induce cell death, U251 cells were treated with rotenone or temozolomide respectively. Rotenone (SigmaAldrich, USA) was dissolved in DMSO (Sigma-Aldrich,
USA) with the final concentration of $1.0 \mu \mathrm{M}$. Temozolomide (Selleck Chemicals, China) was dissolved in DMSO with a final concentration of $100 \mu \mathrm{M}$. After incubation for $24 \mathrm{~h}$, cells in 12-well cell culture plate with glass coverslips were stained by Hoechst 33258 (Beyotime, China) for staining and cell counting. The number of the apoptotic hyperchromatic nucleus and total nucleus were counted in five microscopic fields. The apoptosis index was defined as the mean ratio of apoptotic/total nuclear numbers.

\section{Wound healing assay}

U251 cells were seeded in 6-well plates and incubated to reach $90 \%$ confluence. After serum-starved for $4 \mathrm{~h}$, monolayers were scratched with a sterile $200-\mu \mathrm{L}$ pipette tip to create a wound, and cells were then washed twice with FBS to remove floating cells. Subsequently, cells were cultured in serum-free DMEM medium for additional $48 \mathrm{~h}$. Images were captured using an inverted phase contrast 
microscope at 0,24 and $48 \mathrm{~h}$, and analyzed using the wound-healing macro of ImageJ. The rate of wound closure was calculated based on the area of the gap.

\section{Cell migration and invasion assay}

Chambers with $8.0 \mu \mathrm{m}$ PET membranes in 24-well plates (Corning, USA) were used to measure cell invasion and migration. For migration assay, cells with a density of $2 \times 10^{4}$ cells/well were seeded into the upper chamber of the 24-well transwell insert. The lower chamber was then filled with medium containing $10 \%$ FBS as a chemoattractant. The same number of cells were seeded in another well as a control. After $24 \mathrm{~h}$, the upper surface of the membrane was scrubbed to remove all non-invaded cells. Cells migrated to the lower surface of the filter were fixed and stained with $0.5 \%$ crystal violet solution for counting and quantification. For invasion assay, cells were seeded into the upper chamber precoated with BioCoat Matrigel (BD, USA) according to the manufacturer's protocol. After $48 \mathrm{~h}$, the invasive ability was assessed the same as the migration assay. The invasion index was calculated by ImageJ. All assays were independently repeated for at least three times.

\section{Western blot}

Total cell lysates were prepared by disrupting cells with $2 \%$ SDS lysis containing protease and phosphatase inhibitor cocktails (Thermo Scientific, USA). Protein concentrations were determined using the BCA Protein Assay Reagent (Thermo Scientific), then calibrated using a loading buffer. Equivalent proteins were loaded and separated by SDS-PAGE according to standard procedure. The primary antibodies used in this study were list below (Table 1).

\section{Immunofluorescence}

For immunostaining, U251 cells were seeded in 12-well plates with coverslips $\left(10^{5}\right.$ cell/well $)$ overnight, and fixed in 4\% paraformaldehyde. After permeabilizing with $0.25 \%$ Triton X-100 for 10 min, cells were blocked in $10 \%$ goat serum and incubated with primary antibodies (antiflag, 1:500) and secondary Alexa Fluor ${ }^{\mathrm{TM}} 594$ Goat AntiMouse IgG $(\mathrm{H}+\mathrm{L})$ antibody (Invitrogen, USA). Slides were mounted using Prolong Gold antifade with DAPI. Images were acquired using a fluorescent microscope (Olympus, USA).

\section{RNA extraction and real-time PCR}

For RNA extraction, glioma tissues or cells were homogenized, and total RNA was isolated using Trizol reagent (Invitrogen, USA) according to the manufacturer's instruction. Reverse transcriptase reactions were performed by incubating $400 \mathrm{ng}$ RNA with the first-strand cDNA synthesis kit for subsequent real-time PCR assay. The $2^{-\Delta \Delta \mathrm{Cq}}$ method was used to calculate gene transcription level, with $\beta$-actin mRNA as control. Primer sequences were as list below (Table 2).

\section{Statistical analysis}

All the statistical analyses in this study were calculated by GraphPad Prism 7.0 software (GraphPad, USA). The measurement data were presented as the mean \pm standard deviation (SD). Statistical comparison between two groups was performed by Student's $t$-test, and one-way ANOVA followed by the Bonferroni multiple comparison post hoc tests for multi-group comparisons.

\section{Table 2 Real-time PCR primers}

\begin{tabular}{lll}
\hline Targets & Forward $\mathbf{5}^{\prime} \mathbf{- 3}^{\prime}$ & Reverse $\mathbf{5}^{\prime} \mathbf{- \mathbf { 3 } ^ { \prime }}$ \\
\hline EN2 & CCGGCGTGGGTCTACTGTA & CCTCTTTGTTCGGGTTCTTCTT \\
MMP1 & GGGGCTTTGATGTACCCTAGC & TGTCACACGCTTTTGGGGTTT \\
MMP3 & CGGTTCCGCCTGTCTCAAG & CGCCAAAAGTGCCTGTCTT \\
MMP9 & GGGACGCAGACATCGTCATC & TCGTCATCGTCGAAATGGGC \\
B-actin & CATGTACGTTGCTATCCAGGC & CTCCTTAATGTCACGCACGAT
\end{tabular}

\section{Table 1 Antibodies used in this study}

\begin{tabular}{lll}
\hline Antibodies & & \\
\hline Rabbit monoclonal EN2 antibody & Abcam & Cat\#ab28731 \\
Goat monoclonal EN2 antibody & Abcam & Cat\#ab45867 \\
Mouse monoclonal FLAG antibody & Sigma-Aldrich & Cat\#F3165 \\
Mouse monoclonal Beta actin antibody & Boster Biological Technology & Cat\#BM0627 \\
Rabbit monoclonal Vimentin antibody & Cell Signaling Technology & Cat\#5741 \\
Rabbit monoclonal E-Cadherin antibody & Cell Signaling Technology & Cat\#3195 \\
Rabbit polyclonal STAT3 antibody & Abclonal & Cat\#A16975 \\
Rabbit polyclonal MMP-9 antibody & Cell Signaling Technology & Cat\#3852 \\
Mouse monoclonal GAPDH antibody & Millipore & Cat\#MAB374 \\
\hline
\end{tabular}


Kaplan-Meier survival curve comparison was performed by the log-rank test. The sample sizes (n) were indicated in the figure legends. A p-value $<0.05$ was considered statistically significant.

\section{Results}

\section{EN2 expression is negatively associated with glioma} malignancy

As a first step to identify the possible contributions of EN2 in gliomagenesis, we analyzed the EN2 gene expression profiles in tumor tissues compared with adjacent brain tissues in glioma patients from West China Hospital of Sichuan University (Fig. 1a). By real-time PCR assay, we found that the mRNA level of EN2 was decreased in gliomas compared to adjacent brain tissues (Fig. 1b). Further examinations confirmed that EN2 expression was decreased in high-grade gliomas (WHO III and IV) in contrast to low-grade gliomas (WHO II) (Fig. 1c), suggesting that EN2 expression is associated with lower glioma grade. We also examined the protein level of EN2 using currently commercial antibodies. However, these antibodies were not reliable to detect endogenous EN2 protein, because they cannot even recognize overexpressed EN2 in glioma cell lines (data not shown).

To investigate the correlation of EN2 expression with clinical significance in gliomas, we performed Kaplan-Meier survival analysis and found that gliomas with higher EN2 expression carried a significantly better prognosis than those with lower EN2 expression (Fig. 1d). Taken together, all these findings indicate that EN2 expression is associated with a reduced glioma malignancy.

\section{EN2 overexpression alters gene expression profiles in glioma cells}

Since the expression of EN2 is inversely correlated with glioma malignancy, we sought to determine whether EN2 functionally suppresses gliomagenesis. We conducted a Flag-tagged EN2 overexpressed U251 human glioma cells, in which EN2 is lowly expressed. Real-time PCR and Western blot analysis validated that EN2 is successfully overexpressed in U251 cells (Fig. 2a, b). Moreover, immunostaining images confirmed that overexpressed EN2 was enriched in the nuclear, supporting the fact that EN2 is a homeobox-containing transcription factor (Fig. 2c). It's also noted that EN2 signals were still existed in the cytoplasm, suggesting that EN2 may have functional roles beyond transcription factor.

To investigate the biological functions of EN2 in glioma cells, we performed transcriptome sequencing (RNAseq) in Flag-EN2 overexpressed cells with matched controls. Results showed that Flag-EN2 altered 243 gene expression compared to controls (Fig. 2d). We found that
EN2 overexpression regulated genes in cellular metabolism and transmembrane transport pathway curated by the Kyoto Encyclopedia of Genes and Genomes (KEGG) [29]. We also noted that the genes involved in mitochondrial oxidative phosphorylation (OXPHOs) and respiration machinery were controlled by EN2 (Fig. 2e). EN2 was reported as a transcription factor and therefore may serve as a regulator in nuclear-controlled mitochondrial metabolism. Nevertheless, considering that tumor cells are relying on accelerated nutrient transport and metabolism, it's assumed that EN2 may control cell growth and survival in glioma cells. Indeed, we found that genes in cell proliferation/apoptosis were also controlled by EN2 (Fig. 2e), suggesting that EN2 may participate in glioma tumorigenesis.

\section{EN2 inhibits cell proliferation and promotes cell apoptosis in glioma cells}

To investigate whether EN2 regulates glioma tumorigenesis, we evaluate cell proliferation/apoptosis in U251 cells transfected by Flag-EN2. Results from the CCK-8 assay indicated that EN2 overexpression reduced cell proliferation in glioma cells (Fig. 3a). Consistently, we performed colony formation assay and found that EN2 overexpression impaired colony formation in U251 cells (Fig. 3b, c). Moreover, we confirmed the effect of EN2 on cell proliferation by EdU labeling assay and found that EdU positive cells were slightly decreased in EN2 overexpressed cells, suggesting that EN2 exert an inhibitory effect on glioma proliferation.

Next, we examined the effect of EN2 on cell survival/ apoptosis in glioma cells. Results from flow-cytometry revealed that EN2 overexpression alone did not dramatically induce early apoptosis in U251 cells (Fig. 4a, b). However, by applying rotenone and temozolomide to induce apoptosis, it's found that EN2 overexpression dramatically increased cell apoptosis under pharmacological treatment (Fig. 4c, d), indicating that EN2 sensitizes glioma cells to cell death and synergizes with temozolomide.

\section{EN2 suppresses cell migration/invasion in glioma cells}

A typical feature of glioma is diffuse tumor invasion, and we sought to determine whether EN2 functionally suppresses glioma migration/invasion. Indeed, EN2 overexpression dramatically decreased the migration of U251 cells by wound healing assay (Fig. 5a, b) and transwell migration assay (Fig. 5c, d). Next, we evaluated the effect of EN2 on cell invasion by the Matrigel invasion assay. After $48 \mathrm{~h}$ of incubation, the numbers of cells invaded through the matrigel were calculated, as a result, EN2 

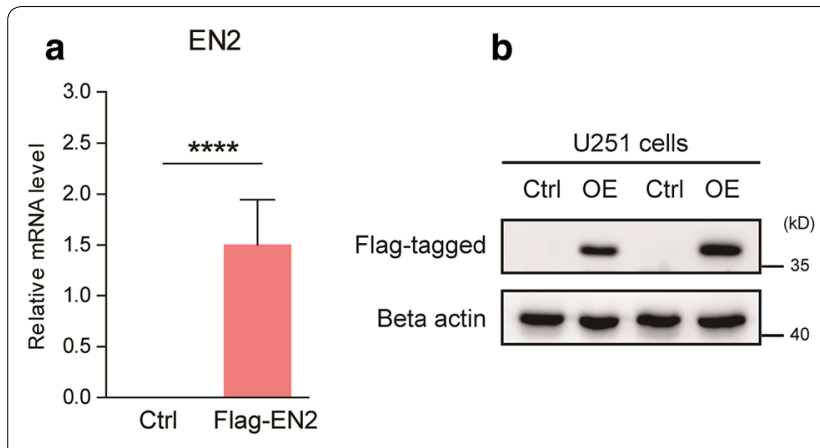
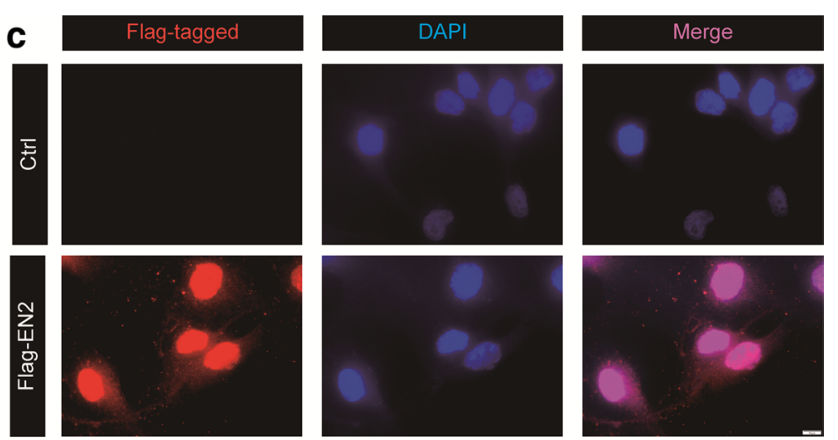

d
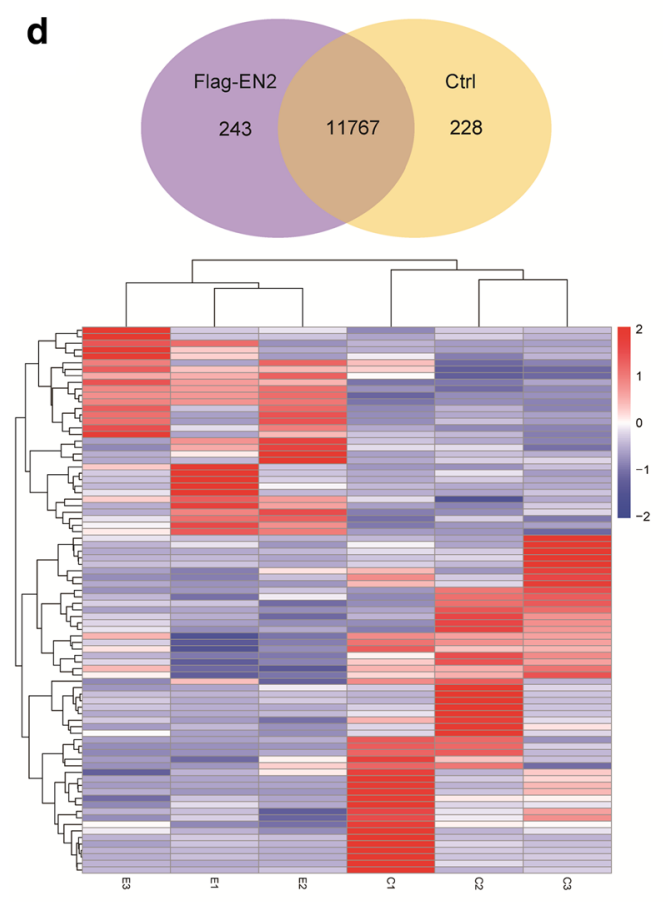

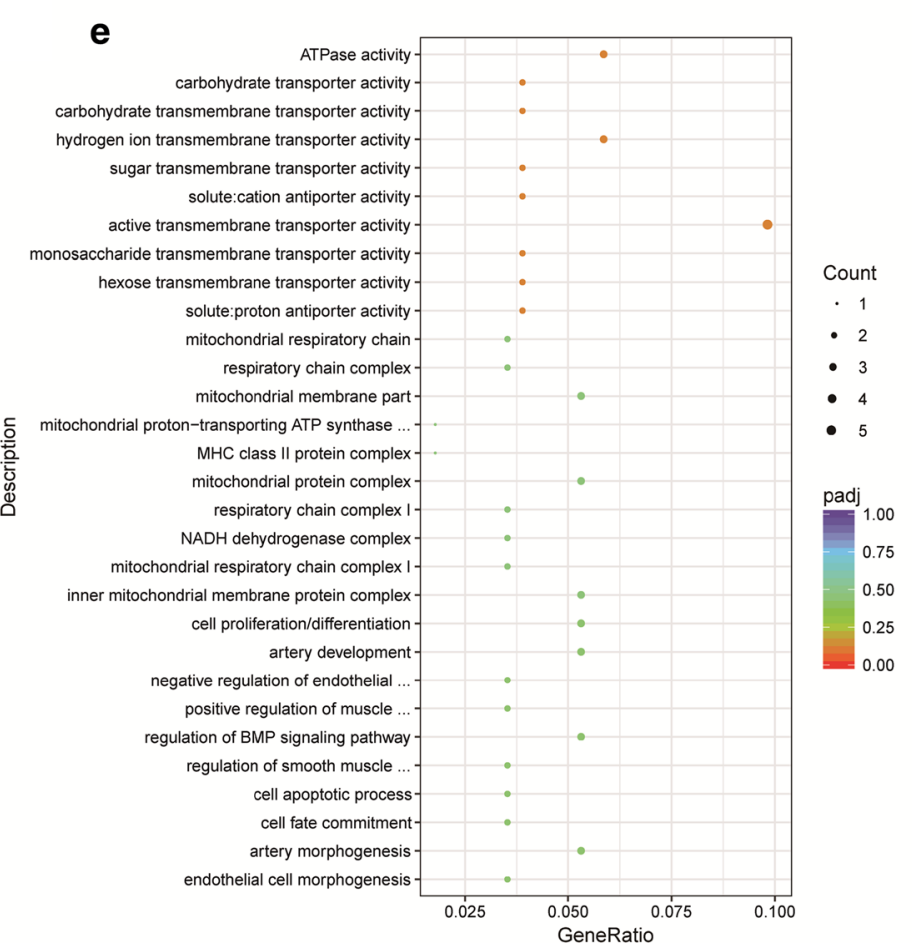

GeneRatio

Fig. 2 EN2 overexpression alters gene expression profiles in glioma cells. $\mathbf{a}$ and $\mathbf{b}$ Validation of EN2 overexpression in U251 cells by Real-time PCR and Western blot $(n=3)$. c Representative images indicating EN2 overexpression in U251 cells locating in the nucleus. $\mathbf{d}$ and e Altered gene profiles of EN2 overexpression by RNA-seq analysis ( $C t r l, n=3 ; O E, n=3)$

overexpression strongly inhibited the invasive ability of U251 cells (Fig. 5e, f).

Tumor invasion is tightly controlled by multiple signaling pathways, including MMPs family. To reveal the molecular mechanism by which EN2 suppresses glioma cell migration/invasion, we examined and found that the protein level of MMP-9 was dramatically decreased by EN2 overexpression (Fig. $5 \mathrm{~g}$, h). However, it's noticed that the mRNA level of MMP-9 was inversely increased by EN2 overexpression (Fig. 5i). Thus, we assume that EN2 may control MMP-9 protein stability/degradation in U251 cells. Indeed, the protein level of MMP-9 was restored by MG132, a proteasome inhibitor to block ubiquitin-conjugated protein degradation (Fig. 5j). Altogether, our results demonstrate that EN2 suppresses cell migration/invasion in glioma cells via MMP-9.

\section{Discussion}

In this study, we investigate the potential role of EN2 in human gliomas, and reveal a novel function of EN2 in regulating cell proliferation/apoptosis/invasion and participating in gliomagenesis. EN2 is a suppressor of glioma tumorigenesis, which is downregulated in human gliomas and negatively associated with glioma malignancy. Elevated EN2 expression inhibits cell proliferation, 


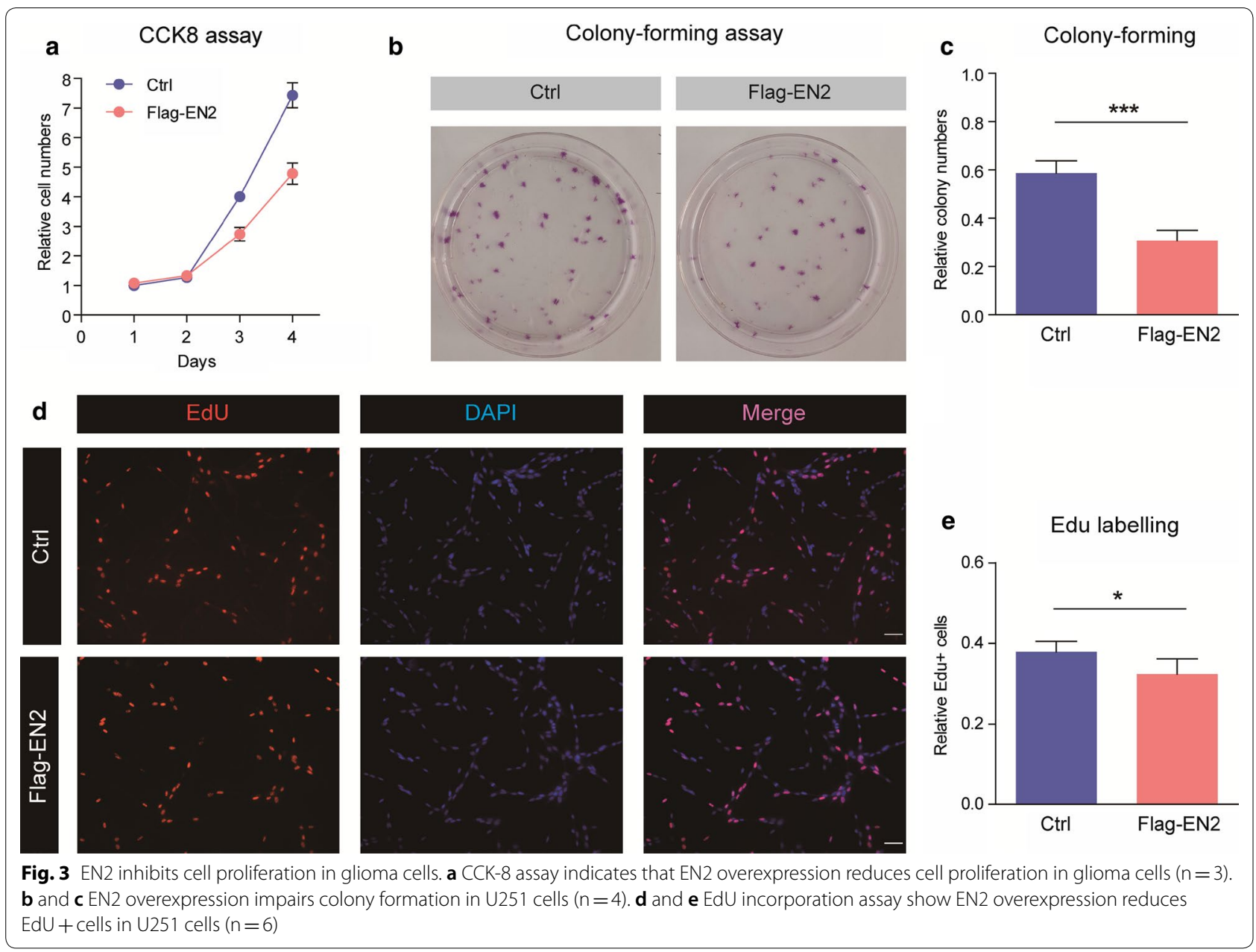

enhances glioma sensitivity to temozolomide and blocks cell invasion of glioma cells. All these results imply a novel function of EN2 in glioma suppression and provide potential targets for glioma therapy (Fig. 5k).

EN2 is a member of the homeobox family, which encodes a homeodomain-containing transcription factor that is essential for early development. Elevation of EN2 has been highly correlated with the proliferation, invasion, and migration in several types of malignancies [18-26], however, controversial results show that EN2 is silenced in other cancers [27-29], and thus EN2 acts as a potential diagnostic and prognostic biomarker [23, 30-33]. However, decreased EN2 in renal carcinoma has been observed and downregulation of EN2 in 786-O cell line promoted proliferation and reduced apoptosis [27, 34, 35]. Thus, it's proposed that EN2 has distinct functions in different types of tumors. In this study, we identify that EN2 is reciprocally associated with glioma malignancy. Low expression of EN2 is observed in the subtype of glioma patients with poor survival, suggesting that EN2 expression is a conceivable biomarker for glioma prognosis. Mechanistically, EN2 inhibits glioma proliferation and invasion, and induces apoptosis. Therefore, EN2 is a nodal point for precise regulation of gliomagenesis.

Mechanistically, EN2 might control cell proliferation and apoptosis through transcriptional regulation. EN2 is a member of the homeobox family transcription factor, and controls multiple cellular events including cellular metabolism and transmembrane transport. Therefore, EN2 may be involved in the regulation of glioma growth and survival. Interestingly, we noted that EN2 also plays a vital role in regulating cell invasion of glioma cells. Extensive infiltration of invasive cells into surrounding normal tissue is a typical feature of glioma development. Current understandings on glioma invasion reveal that the MMP family is a master regulator of tumor invasion. Particularly, MMP-9, a key member of the MMP family, is linked to metastasis in a variety of cancer types [36]. Increased 


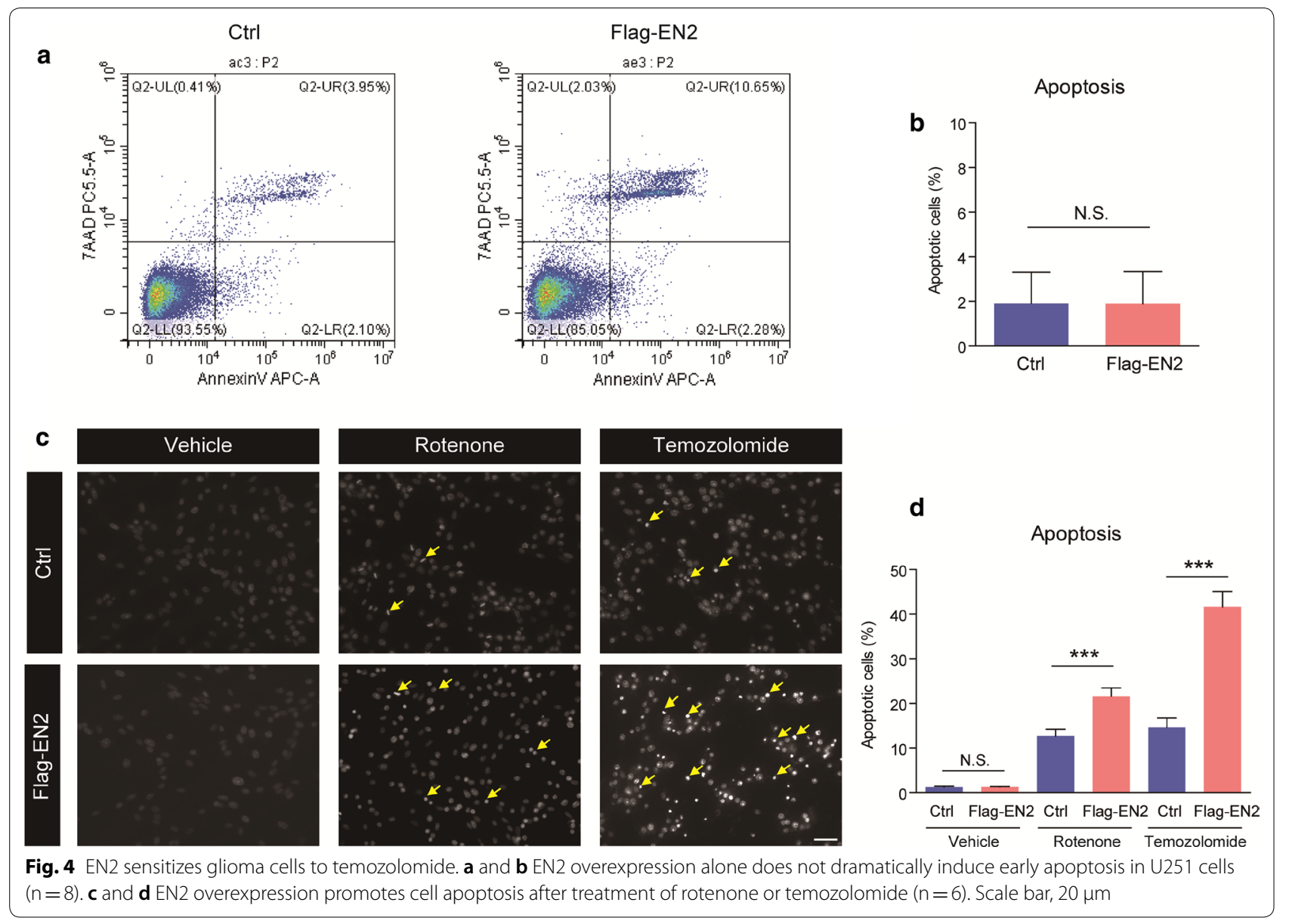

expression of MMP-9 has been found in glioma tissues [37]. Thus, MMP9 is considered as an important regulatory factor for the migration and invasion of gliomas. Our work demonstrates that EN2 overexpression dramatically silences MMP-9 expression by controlling its degradation. This finding extends current knowledge to EN2 functions beyond transcriptional regulation and reveals that EN2 may also exist in the cytoplasm to control protein stability. Future work should focus on the mechanistic studies of how EN2 is involved in the protein degradation system.

\section{Conclusion}

Our study demonstrates that EN2 is a novel suppressor of glioma tumorigenesis by decreasing cell proliferation and invasion, as well as increasing cell apoptosis. All these findings indicate that EN2 is a potential target for precision therapeutics of glioma. 


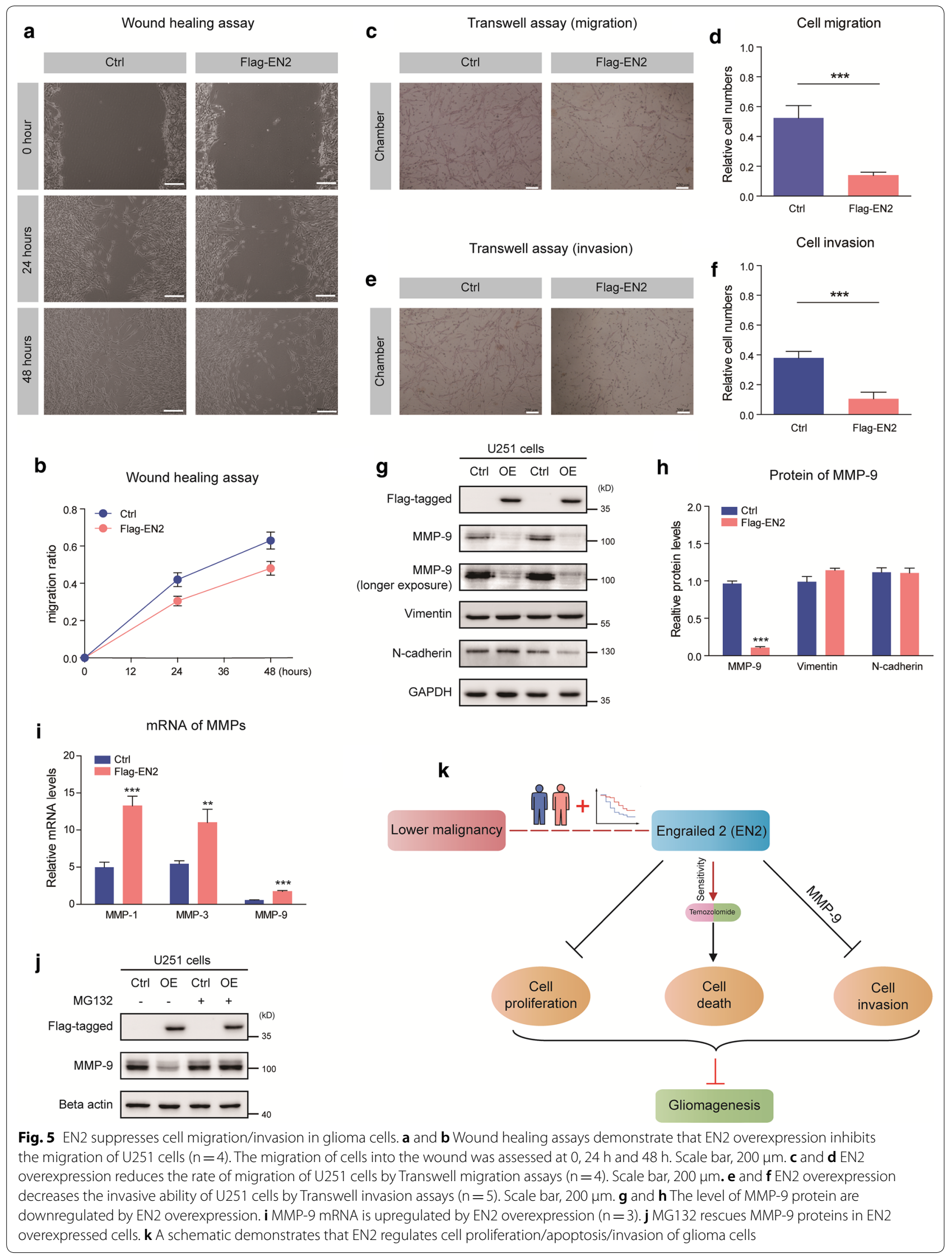




\section{Acknowledgements \\ Not applicable.}

\section{Authors' contributions}

$T L, W Y, M C$ and $Y L$ designed the study and wrote the manuscript. TL, WY, ML, $S Z, X Z, M Z$ and QY performed the experiments and analyzed the data. All authors read and approved the final manuscript.

\section{Funding}

This work was supported by the grant from Sichuan Province Science and Technology Support Program (2017SZ0006 to Dr. Yanhui Liu).

\section{Availability of data and materials}

The datasets generated and/or analyzed during the current study are available from the corresponding author on reasonable request.

\section{Ethics approval and consent to participate}

This study was approved by the Institutional Review Board of West China Hospital of Sichuan University and all patients provided written informed consent.

\section{Consent for publication}

Not applicable.

\section{Competing interests}

The authors declare that they have no conflict of interest.

Received: 29 November 2019 Accepted: 19 February 2020

Published online: 02 March 2020

\section{References}

1. Puchalski RB, Shah N, Miller J, Dalley R, Nomura SR, Yoon JG, Smith KA, Lankerovich M, Bertagnolli D, Bickley K, et al. An anatomic transcriptional atlas of human glioblastoma. Science (New York, NY). 2018;360(6389):660-3.

2. Omuro A, DeAngelis LM. Glioblastoma and other malignant gliomas: a clinical review. JAMA. 2013;310(17):1842-50.

3. Louis DN, Ohgaki H, Wiestler OD, Cavenee WK, Burger PC, Jouvet A, Scheithauer BW, Kleihues P. The 2007 WHO classification of tumours of the central nervous system. Acta Neuropathol. 2007;114(2):97-109.

4. Weller M, Wick W, Aldape K, Brada M, Berger M, Pfister SM, Nishikawa R, Rosenthal M, Wen PY, Stupp R, et al. Glioma. Nat Rev Dis Primers. 2015:1:15017.

5. Stupp R, Hegi ME, Mason WP, van den Bent MJ, Taphoorn MJ, Janzer RC, Ludwin SK, Allgeier A, Fisher B, Belanger K, et al. Effects of radiotherapy with concomitant and adjuvant temozolomide versus radiotherapy alone on survival in glioblastoma in a randomised phase III study: 5-year analysis of the EORTC-NCIC trial. Lancet Oncol. 2009;10(5):459-66.

6. Hottinger AF, Stupp R, Homicsko K. Standards of care and novel approaches in the management of glioblastoma multiforme. Chin $J$ Cancer. 2014;33(1):32-9.

7. Jhanwar-Uniyal M, Labagnara M, Friedman M, Kwasnicki A, Murali R. Glioblastoma: molecular pathways, stem cells and therapeutic targets. Cancers. 2015:7(2):538-55.

8. Lee SY. Temozolomide resistance in glioblastoma multiforme. Genes Dis 2016;3(3):198-210.

9. Jornsten R, Abenius T, Kling T, Schmidt L, Johansson E, Nordling TE, Nordlander B, Sander C, Gennemark P, Funa K, et al. Network modeling of the transcriptional effects of copy number aberrations in glioblastoma. Mol Syst Biol. 2011;7:486.

10. Davidson $\mathrm{EH}$. The regulatory genome: gene regulatory networks in development and evolution. Burlington: Academic; 2006. p. xi.

11. Darnell JE. Transcription factors as targets for cancer therapy. Nat Rev Cancer. 2002;2(10):740-9.

12. Brennan CW, Verhaak RG, McKenna A, Campos B, Noushmehr H, Salama SR, Zheng S, Chakravarty D, Sanborn JZ, Berman SH, et al. The somatic genomic landscape of glioblastoma. Cell. 2013;155(2):462-77.
13. Cancer Genome Atlas Research N. Comprehensive genomic characterization defines human glioblastoma genes and core pathways. Nature. 2008:455(7216):1061-8.

14. Parsons DW, Jones S, Zhang X, Lin JC, Leary RJ, Angenendt $P$, Mankoo P, Carter H, Siu IM, Gallia GL, et al. An integrated genomic analysis of human glioblastoma multiforme. Science (New York, NY). 2008;321(5897):1807-12.

15. Zhang X, Piano I, Messina A, D'Antongiovanni V, Cro F, Provenzano G, Bozzi Y, Gargini C, Casarosa S. Retinal defects in mice lacking the autismassociated gene Engrailed-2. Neuroscience. 2019;408:177-90.

16. Zunino G, Messina A, Sgado P, Baj G, Casarosa S, Bozzi Y. Brain-derived neurotrophic factor signaling is altered in the forebrain of Engrailed-2 knockout mice. Neuroscience. 2016;324:252-61.

17. Genestine $M$, Lin L, Durens M, Yan Y, Jiang Y, Prem S, Bailoor K, Kelly B, Sonsalla PK, Matteson PG, et al. Engrailed-2 (En2) deletion produces multiple neurodevelopmental defects in monoamine systems, forebrain structures and neurogenesis and behavior. Hum Mol Genet. 2015;24(20):5805-27.

18. Martin NL, Saba-El-Leil MK, Sadekova S, Meloche S, Sauvageau G. EN2 is a candidate oncogene in human breast cancer. Oncogene. 2005:24(46):6890-901.

19. Marszall MP, Sroka W, Adamowski M, Slupski P, Jarzemski P, Siodmiak J, Odrowaz-Sypniewska G. Engrailed-2 protein as a potential urinary prostate cancer biomarker: a comparison study before and after digital rectal examination. Eur J Cancer Prev. 2015;24(1):51-6.

20. Pandha H, Sorensen KD, Orntoft TF, Langley S, Hoyer S, Borre M, Morgan R. Urinary engrailed-2 (EN2) levels predict tumour volume in men undergoing radical prostatectomy for prostate cancer. BJU Int. 2012;110(6 Pt B):E287-92

21. Chen JL, Li J, Kiriluk KJ, Rosen AM, Paner GP, Antic T, Lussier YA, Vander Griend DJ. Deregulation of a Hox protein regulatory network spanning prostate cancer initiation and progression. Clin Cancer Res. 2012;18(16):4291-302.

22. Javed S, Langley SE. Importance of HOX genes in normal prostate gland formation, prostate cancer development and its early detection. BJU Int 2014;113(4):535-40.

23. Morgan R, Bryan RT, Javed S, Launchbury F, Zeegers MP, Cheng KK, James ND, Wallace DMA, Hurst CD, Ward DG, et al. Expression of Engrailed-2 (EN2) protein in bladder cancer and its potential utility as a urinary diagnostic biomarker. Eur J Cancer. 2013;49(9):2214-22.

24. Morgan R, Boxall A, Bhatt A, Bailey M, Hindley R, Langley S, Whitaker HC Neal DE, Ismail M, Whitaker $\mathrm{H}$, et al. Engrailed-2 (EN2): a tumor specific urinary biomarker for the early diagnosis of prostate cancer. Clin Cancer Res. 2011;17(5):1090-8.

25. Lin X, Liu X, Gong C. Expression of engrailed homeobox 2 regulates the proliferation, migration and invasion of non-small cell lung cancer cells. Oncol Lett. 2018;16(1):536-42.

26. McGrath SE, Annels N, Madhuri TK, Tailor A, Butler-Manuel SA, Morgan R, Pandha H, Michael A. Engrailed-2 (EN2) - a novel biomarker in epithelial ovarian cancer. BMC Cancer. 2018;18(1):943.

27. Lai CY, Xu Y, Yu GS, Wu X, Li YF, Pan B, Heng BL, Xue YJ, Su ZX. Engrailed-2 might play an anti-oncogenic role in clear-cell renal cell carcinoma. J Mol Histol. 2016;47(3):229-37.

28. Lai $C Y, Y u$ GS, Xu Y, Wu X, Heng BL, Xue YJ, Su ZX. Engrailed-2 promoter hyper-methylation is associated with its downregulation in clear cell renal cell carcinoma. Oncol Lett. 2017;14(6):6888-94.

29. Kanehisa M, Goto S. KEGG: kyoto encyclopedia of genes and genomes. Nucleic Acids Res. 2000;28(1):27-30.

30. Greer PL, Greenberg ME. From synapse to nucleus: calcium-dependent gene transcription in the control of synapse development and function. Neuron. 2008;59(6):846-60.

31. McGrath SE, Michael A, Morgan R, Pandha H. EN2 in prostate cancer. Adv Clin Chem. 2015;71:47-76.

32. Killick E, Morgan R, Launchbury F, Bancroft E, Page E, Castro E, Kote-Jarai Z, Aprikian A, Blanco I, Clowes V, et al. Role of Engrailed-2 (EN2) as a prostate cancer detection biomarker in genetically high risk men. Sci Rep. 2013:3:2059.

33. Rosa MID, Dondossola ER, Alexandre MCM, Madeira K, Cardoso FA, Grande AJ. Urinary EN-2 to predict prostate cancer: systematic review and meta-analysis. Rev Assoc Med Bras (1992). 2017;63(7):656-61. 
34. Lai CY, Pan B, Luo Y, Liang WB, Chen J, Ye DM, Guo JN, Li L, Su ZX. Engrailed-2 is down-regulated but also ectopically expressed in clear cell renal cell carcinoma. Mol Biol Rep. 2014;41 (6):3651-7.

35. Guan R, Xu Y, Lei H, Gao Z, Xin Z, Guo Y. A novel protein is lower expressed in renal cell carcinoma. Int J Mol Sci. 2014;15(5):7398-408.

36. Shay G, Lynch CC, Fingleton B. Moving targets: emerging roles for MMPs in cancer progression and metastasis. Matrix Biol. 2015;44-46:200-6.

37. Rao JS, Yamamoto M, Mohaman S, Gokaslan ZL, Fuller GN, StetlerStevenson WG, Rao VH, Liotta LA, Nicolson GL, Sawaya RE. Expression and localization of $92 \mathrm{kDa}$ type IV collagenase/gelatinase B (MMP-9) in human gliomas. Clin Exp Metas. 1996;14(1):12-8.

\section{Publisher's Note}

Springer Nature remains neutral with regard to jurisdictional claims in published maps and institutional affiliations.
Ready to submit your research? Choose BMC and benefit from:

- fast, convenient online submission

- thorough peer review by experienced researchers in your field

- rapid publication on acceptance

- support for research data, including large and complex data types

- gold Open Access which fosters wider collaboration and increased citations

- maximum visibility for your research: over 100M website views per year

At BMC, research is always in progress.

Learn more biomedcentral.com/submissions 